\title{
Effectiveness of Neuromuscular Electrical Stimulation on Auxiliary Respiratory Muscles in Patients with Chronic Obstructive Pulmonary Disease Treated in the Intensive Care Unit
}

\author{
Dilek KOÇAN KURTOĞLU ${ }^{1}$, Nurettin TAŞTEKIN ${ }^{1}$, Murat BIRTANE${ }^{1}$, Erhan TABAKOĞLU², Necdet SÜT ${ }^{3}$ \\ 'Department of Physical Medicine and Rehabilitation, Trakya University Faculty of Medicine, Edirne, Turkey \\ ${ }^{2}$ Department of Pulmonary Medicine, Trakya University Faculty of Medicine, Edirne, Turkey \\ ${ }^{3}$ Department of Biostatistic, Trakya University Faculty of Medicine, Edirne, Turkey
}

\begin{abstract}
Objective: Chronic obstructive pulmonary disease is a major public health problem. In the present study, we aimed to investigate the possible effects of upper extremity exercises and neuromuscular electrical stimulation therapy applied to auxiliary respiratory muscles on arterial blood gases, blood pressure, heart rate values, and quality of life in patients with chronic obstructive pulmonary disease.

Material and Methods: Thirty patients who were diagnosed with stage 4 severe chronic obstructive pulmonary disease by a pulmonologist and who needed intensive care were included in the study. The patients were equally allocated into two groups containing 15 patients each: control and intervention. Both groups were given an unassisted upper extremity exercise program for four weeks, and only one group was given neuromuscular electrical stimulation on auxiliary respiratory muscles for 10 days. Arterial blood gas measurements, peak heart rate, and breathing frequency were recorded. St. George's Respiratory Questionnaire and short form-36 were performed for the evaluation of the quality of life. Functional capacity was determined by functional independent measurement. Evaluations of the patients were performed on the $1^{\text {st }}, 8^{\text {th }}, 15^{\text {th }}$, and $30^{\text {th }}$ days of the study. Results: There were statistically significant improvements in peak heart rate, breathing frequency per minute, and functional independency scores in the group where exercise and neuromuscular electrical stimulation had been concomitantly applied $(p<0.05)$.

Conclusion: This study revealed positive effects of neuromuscular electrical stimulation in addition with therapeutic exercises on the cardiorespiratory system in the short run.

Keywords: Chronic obstructive pulmonary disease, neuromuscular electrical stimulation, breathing exercise
\end{abstract}

\section{Introduction}

Pulmonary rehabilitation has gained importance in the treatment of respiratory diseases, especially since over the last decades. Pulmonary rehabilitation mainly consists of two components: "physical exercise" and "self-management." Exercise therapy includes training of the lower limb muscles (e.g., bicycle, treadmill, walking), upper limb muscles (e.g., stationary bicycle for the arms), and respiratory muscles for increasing strength and endurance.
The self-management program predominantly aims to instruct the patient about the disease and prevent further complications (1).

The rate of chronic obstructive pulmonary disease (COPD) is still high in developed countries, although the main risk factors such as smoking habit and air pollution magnitude tend to decrease (2). Dyspnea, muscle weakness, exercises intolerance, deterioration in the quality of life, and emotional disturbances are frequently observed in COPD patients $(3,4)$.

Address for Correspondence: Nurettin Taştekin, MD, Department of Physical Medicine and Rehabilitation, Trakya University Faculty of Medicine, Edirne, Turkey. Phone: +90 28423576 41/4715 E-mail: zentastekin@yahoo.com 
Proper pulmonary rehabilitation performed in COPD patients increases their response rates to therapy and decreases their disability and mortality $(4,5)$. The rehabilitation program performed in COPD patients who are in need of intensive care consists of positioning, passive and active exercises, continuous rotation, percussion and vibration, respiratory and peripheral muscle stretching exercises, or electrical stimulation to these muscles (6). Breathing exercises are used to decrease dyspnea in non-intubated patients. It has been shown that peripheral muscle training in COPD patients aids patients relieve from respiratory failure and leads to a significant increase in the exercise capacity of patients (4-6).

Neuromuscular electrical stimulation (NMES) is frequently performed to preserve or improve muscle mass, strength, and function, especially in the impaired muscles of immobilized patients. NMES stimulates targeted motor neurons with a low voltage to increase muscle strength in COPD patients who are on a mechanical ventilator to decrease the respiratory speed (7).

In this study, we aimed to investigate the possible effects of NMES in combination with pulmonary rehabilitation on arterial blood gases, blood pressure, heart rate values, and quality of life in stage 4 severe COPD patients.

\section{Material and Methods}

\section{a. Patient selection}

Thirty patients (28 males, 2 females) who were diagnosed with stage 4 severe COPD, as defined by Global Initiative for Chronic Lung Disease (GOLD) (8), by a pulmonologist who needed invasive mechanical ventilation in the intensive care unit (ICU) were included in the study. The patients were equally allocated to two groups: control and intervention. Each group contained 15 patients. The patients were randomized with regard to application turn according to the equation $n, n+2, n+4$ for the control group and $n+1, n+3, n+5$ for the intervention group.

\section{Inclusion criteria}

a. COPD patients who developed respiratory failure

b. Patients satisfying the criteria for the need of ICU

c. Patients who were followed for at least $24 \mathrm{~h}$ in the ICU

\section{Exclusion criteria}

a. Unstable cardiovascular disease (unstable angina, aortic valve disease)

b. Uncontrolled hypertension

c. Malignancy

e. Liver and/or kidney failure

f. Severe systemic chronic diseases

g. Orthopedic problems (fracture, joint subluxation, etc.) that could interfere with rehabilitation programs

h. The patients with fever and who are under the probable effects of acute medication changes were not included in the study

\section{b. Treatment applications}

The duration of the study was four weeks. The study protocols were approved by the "Trakya University Faculty of Medicine, Ethics Committee." Informed consent was obtained from all patients prior to their inclusion to the study.

\section{Control group}

The patients in this group were prescribed upper extremity range of motion (ROM) exercises. Shoulder flexion, extension, abduction, adduction and rotation and elbow flexion and extension ROM exercises were applied passively by a physician for 30 days. During the early stages, the duration of the program was as long as the patient could tolerate and was 10 min a day on following days.

After the patients left the ICU, they had a chest physiotherapy program including controlled breathing techniques. After leaving the ICU, the patient's relatives were instructed about controlled breathing techniques and pulmonary physiotherapy. Patients were applied $15 \mathrm{~min}$ percussion and vibration ( 5 min of session, three times a day). They performed pursed lips breathing and diaphragmatic breathing exercises for 5 min each day.

\section{Intervention group}

The patients in this group had the same upper extremity ROM exercises and after ICU programs as those in the control group. Additionally, NMES to auxiliary respiratory muscles was applied 20 min a day. NMES was applied to the pectoral major, trapezius, and latissimus dorsi muscles for the first 10 days with a COMPEX device (MI theta PRO, Switzerland). The amplitude was switched between 20 and $25 \mathrm{~mA}$ according to the patients' tolerance, and the wave frequency was $50 \mathrm{~Hz}$. Biphasic symmetrical waves with $6 \mathrm{~s}$ duration of contraction, $1.5 \mathrm{~s}$ of increase, and $0.75 \mathrm{~s}$ of decrease were used.

\section{c. Measurements}

- Evaluation of the patients was performed on the $1^{\text {st }}, 8^{\text {th }}$, $15^{\text {th }}$, and $30^{\text {th }}$ days of the study.

- Arterial blood gas measurements were taken with a blood gas analyzer in the central laboratory (Roche Cobas b 2-21, Japan).

- Peak heart rate per minute was measured in all patients (During the day, the values were determined before the first medical treatment).

- Breathing frequency per minute was evaluated (During the day, the values were determined before the first medical treatment).

- St. George's Respiratory Questionnaire (SGRQ) and short form-36 (SF-36) were evaluated for the evaluation assessment of the quality of life. During the inquiry, the patients' relatives held to answer questions if the patient had an unconscious state.

- Functional capacity was determined by functional independent measurement (FIM).

\section{Arterial blood gas measurement}

Blood samples were taken from the radial or femoral arteries of the patients with heparin washed injector's obeying the rules of infection protection, and they were sent to the central laboratory of the Hospital in $20 \mathrm{~min}$. The blood samples were preserved in ice in $2 \mathrm{ml}$ syringes with heparin and were analyzed $1 \mathrm{~h}$ after their collection using gas testing equipment (Roche Cobas b 2-21, Japan) for determining the oxygen saturation. Blood gas measurements of the patients were repeated on $1^{\text {st }}$, $8^{\text {th }}, 15^{\text {th }}$ and $30^{\text {th }}$ days during hospitalization. 
Saint George's Respiratory Questionnaire

- The study participants filled the SGRQ form at the beginning and 30 days after the intervention.

- SGRO investigates the quality of life related to pulmonary diseases. It is a validated and self-administered questionnaire in this area.

- It has 50 questions enquiring about respiratory symptom activity limitations caused by breathlessness and the overall effect of pulmonary disease on social and psychological functioning.

- The scoring is between 0 and 100, and 100 denotes the most severe symptoms and limitations (9).

Short Form-36 Quality of Life Questionnaire

- The study participants filled the SF-36 form at the beginning and 30 days after the intervention.

- The quality of life was measured by the SF-36 survey, which is valid and reliable in Turkish. It investigates eight major headings by asking 36 questions.

- Here, 10 items evaluate physical functioning, four items physical role, two items bodily pain, five items general health, four items vitality, two items social functioning, three items emotional role, and five items mental health.

- Evaluation range is between 0 and 100 for each item, 100 being the best score (10).

\section{Functional independent measurement scale}

Functional independent measurement is an 18-item instrument that assesses disability in terms of what level of assistance an individual needs to perform various activities. FIM assesses independence in functional skills such as dressing, bathing, eating, mobility, locomotion, communication, and social interaction. In terms of construct validity, the FIM instrument measures two-dimensional domains of motor and cognitive functions. Each item is assessed by a clinician on a scale of 1 (total assistance) to 7 (complete independence) (11).

\section{d. Statistical analysis}

Results were expressed as mean \pm standard deviation. The normality distribution of the numerical variables was tested using the one sample Kolmogorov-Smirnov test. Differences between the intervention and control groups were compared using the Student's t-test for normally and the Mann-Whitney $U$ test for non-normally distributed data. Four different measurements $\left(1^{\text {st }}, 8^{\text {th }}, 15^{\text {th }}\right.$, and $30^{\text {th }}$ days) in each group were compared using the repeated measures ANOVA test, and then, Bonferroni post hoc test was used for multiple comparisons when a significant difference was obtained. Covariance analysis (ANCOVA test) was used for the comparison of change from the $1^{\text {st }}$ to $30^{\text {th }}$ days between the intervention and control groups. Statistical Package for the Social Sciences 20.0 (IBM SPSS Inc., Chicago, IL, USA) statistical software was used for statistical analysis. A $p$ value of $<0.05$ was considered as statistically significant.

\section{Results}

There were no significant differences with regard to demographic parameters between the groups (Table 1). At the end of the third day, six patients in the control group and four patients in the intervention group could not relieve from ventilator. No significant differences could be found in terms of weaning from mechanical ventilation duration between the groups $(p=0.471$, Table 2$)$.

Peak heart rate per minute values were significantly different between the group on the $15^{\text {th }}$ and $30^{\text {th }}$ days $(p<0.001, p=0.008$, respectively). Evaluation on the first and eighth days did not reveal a significant difference in terms of peak heart rate per minute values $(p=0.478, p=0.092$, respectively). The comparison of peak heart rate per minute measurements between the baseline and the end of the study on the $30^{\text {th }}$ day showed significant intragroup changes in both groups $(\mathrm{p}=0.03, \mathrm{p}<0.001)$ (Table 3$)$.

The mean respiratory rate values on the $30^{\text {th }}$ day were found to be significantly different between the groups $(p=0.003)$. Respiratory rate values on the $1^{\text {st }}, 8^{\text {th }}$, and $15^{\text {th }}$ days were not different ( $p>0.05)$. Intra-group variations in both groups between the baseline and $30^{\text {th }}$ day were significantly different $(p<0.001)$ (Table 3$)$.

Oxygen saturation values were found to be different between the groups on the $8^{\text {th }}$ day $(p=0.01)$. The $1^{\text {st }}, 15^{\text {th }}$, and $30^{\text {th }}$ day evaluations did not reveal differences with regard to oxygen saturation ( $p>0.05)$. While there were differences in oxygen saturation in the intervention group between the baseline and the end of the third day $(p=0.005)$, it could not be found in the control group ( $p>0.05)$.

All the parameters of SGRQ (symptoms, activity, impact, and total) were not significantly different at the baseline and $30^{\text {th }}$ day between both groups ( $>00.05)$. Parameters other than "activity" changed significantly from the baseline to the $30^{\text {th }}$ day in both groups $(p<0.05)$ (Figure 1, 2).

Table 1. The demographic characteristics of patients

\begin{tabular}{lccc} 
& $\begin{array}{c}\text { Control group } \\
\text { Mean } \pm \text { SD }\end{array}$ & $\begin{array}{c}\text { Intervention group } \\
\text { Mean } \pm \text { SD }\end{array}$ & $\mathbf{p}$ \\
\hline Female & 1 & 1 & \\
Male & 14 & 14 & \\
Age (year) & $69.93 \pm 11.0$ & $66.06 \pm 13.86$ & $>0.05$ \\
& $(50-87)$ & $(40-88)$ & \\
Weight $(\mathrm{kg})$ & $76.40 \pm 15.9$ & $76.93 \pm 18.66$ & $>0.05$ \\
& $(50-110)$ & $(48-100)$ & \\
Height $(\mathrm{cm})$ & $172.26 \pm 7.39$ & $170.66 \pm 10.04$ & $>0.05$ \\
& $(160-180)$ & $(152-185)$ & \\
BMl $\left(\mathrm{kg} / \mathrm{m}^{2}\right)$ & $25.66 \pm 4.5$ & $26.63 \pm 7.39$ & $>0.05$ \\
& $(17.30-33.95)$ & $(17.30-41.12)$ & \\
Disease duration (year) & $10.73 \pm 12.9$ & $8.33 \pm 7.68$ & $>0.05$ \\
& $(1-50)$ & $(1-30)$ & \\
Smoking (pack/year) & $34.53 \pm 19.5$ & $30.26 \pm 16.76$ & $>0.05$ \\
& $(0-65)$ & $(0-50)$ & \\
\hline
\end{tabular}

BMI: body mass index

Table 2. Average length of stay on mechanical ventilation

\begin{tabular}{lccc} 
& $\begin{array}{c}\text { Control group } \\
\text { Mean } \pm \text { SD }\end{array}$ & $\begin{array}{c}\text { Intervention group } \\
\text { Mean } \pm \text { SD }\end{array}$ & $\mathbf{p}$ \\
\hline Average length of stay & $18.13 \pm 11.08$ & $14.60 \pm 10.97$ & $>0.05$ \\
on mechanical ventilation & $(3-30)$ & $(3-30)$ &
\end{tabular}


Table 3. Peak heart rate and breathing frequency per minute on different visit days

\begin{tabular}{|c|c|c|c|c|c|c|}
\hline & \multicolumn{2}{|c|}{ Peak heart rate per minute } & \multirow[b]{2}{*}{ p } & \multicolumn{2}{|c|}{ Breathing frequency per minute } & \multirow[b]{2}{*}{$\mathbf{p}$} \\
\hline & $\begin{array}{l}\text { Control group } \\
\text { Mean } \pm S D\end{array}$ & $\begin{array}{c}\text { Intervention group } \\
\text { Mean } \pm \text { SD }\end{array}$ & & $\begin{array}{l}\text { Control group } \\
\text { Mean } \pm S D\end{array}$ & $\begin{array}{c}\text { Intervention group } \\
\text { Mean } \pm \text { SD }\end{array}$ & \\
\hline $1^{\text {st }}$ day & $106.66 \pm 23.77(82-180)$ & $101.40 \pm 5.43(85-130)$ & $>0.05$ & $25.93 \pm 4.18(20-35)$ & $27.73 \pm 3.19(22-32)$ & $>0.05$ \\
\hline $8^{\text {th }}$ day & $98.73 \pm 14.82(80-132)$ & $91.00 \pm 8.66(75-102)$ & $>0.05$ & $24.53 \pm 3.60(18-30)$ & $24.60 \pm 3.45(20-30)$ & $>0.05$ \\
\hline $15^{\text {th }}$ day & $95.73 \pm 12.56(78-122)$ & $85.00 \pm 8.00(70-95)$ & $<0.001^{*}$ & $23.26 \pm 3.41(18-28)$ & $21.53 \pm 3.60(16-28)$ & $>0.05$ \\
\hline $30^{\text {th }}$ day & $90.73 \pm 12.28(75-120)$ & $80.20 \pm 7.36(70-90)$ & $<0.01^{*}$ & $21.86 \pm 3.71(16-28)$ & $17.66 \pm 3.24(14-24)$ & $<0.001^{*}$ \\
\hline
\end{tabular}

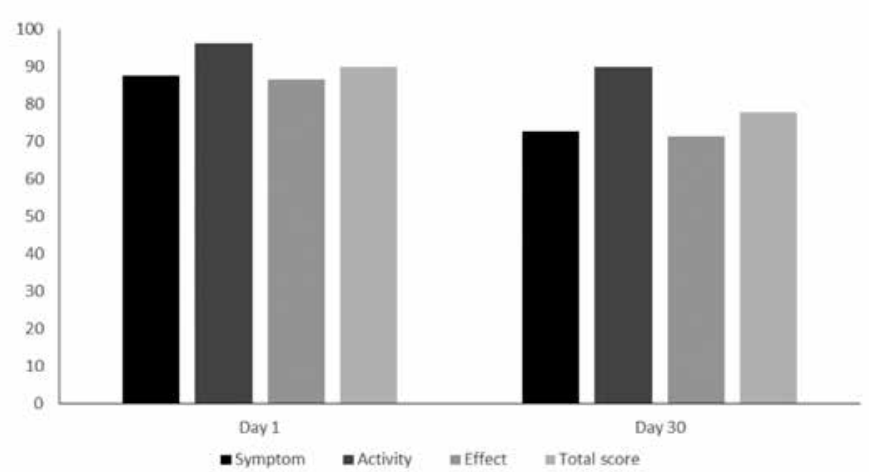

Figure 1. Sub-group and total scores of patients in the control group. The distribution of parameters in Saint George's Respiratory Questionnaire

Physical function scores, which are a subset of SF-36, improved significantly from the baseline to the $30^{\text {th }}$ day in both control and intervention groups $(p=0.02, p=0.021)$. Improvement in body pain scores was significant in the intervention group $(\mathrm{p}=0.034)$ but not in the control group, whereas general health, vitality, and social function parameters changed significantly in both groups. The significant improvement of emotional role score found in the control group ( $p=0.019)$ was not observed in the intervention group $(p>0.05)$. Mental health seemed to recover significantly in both groups after the study period $(p<0.001)$.

All subsets (motor score, cognitive score) and overall scores of FIM improved significantly in both groups from the first day to the last.

\section{Discussion}

COPD is a common disease characterized by acute attacks of respiratory distress affecting the quality of life of patients and is an important cause of mortality and morbidity. According to data in 2000, the number of patients diagnosed with COPD in the world was 52 million, and 2.74 million died as a result of COPD. Acute attacks are the most important cause of morbidity and mortality, and the mean number of attacks per year was found to be 3 . The harms of smoking are described to patients through instruction programs consisting of exercises and controlled breathing techniques to prevent acute attacks $(12,13)$.

Dyspnea and peripheral muscle weakness cause deteriorations in the quality of life and activities of daily living in ICU pa-

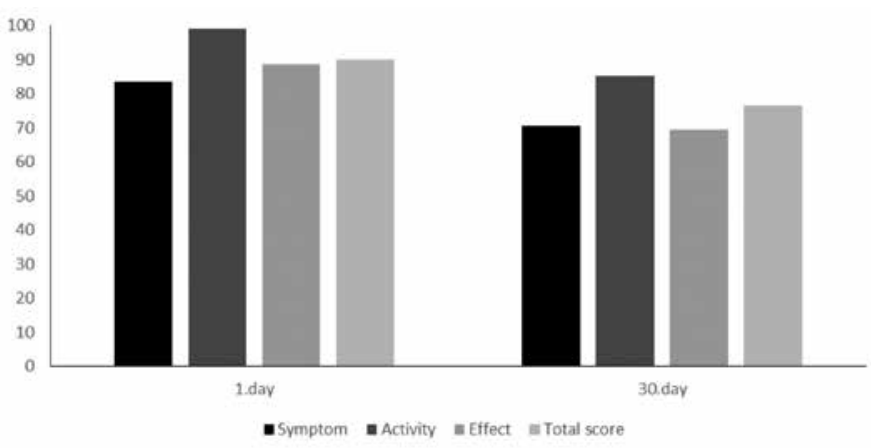

Figure 2. Sub-group and total scores of patients in the intervention group. The distribution of parameters in Saint George's Respiratory Questionnaire

tients with COPD. Positioning, mobilization, manual hyperinflation, and respiratory physiotherapy treatment programs are the usual interventions applied to these patients in the ICU. Patients in need of intensive care experience difficulties in participation in pulmonary rehabilitation programs as they are very weak in terms of physical capacity. There are many studies on the effectiveness of mobilization in ICU patients with COPD (14). Nava et al. (15) investigated the effectiveness of the rehabilitation program consisting of active lower/upper extremity exercises and progressive mobilization activities that are added to the standard medical therapy for exercise tolerance and dyspnea in COPD patients with respiratory failure connected to the mechanical ventilator. As a result, they reported that the pulmonary rehabilitation program was successful to help develop exercise tolerance and reduce dyspnea. They recommended early pulmonary rehabilitation programs to COPD patients treated in the ICU. We tried to define the efficacy of upper extremity exercises and NMES on mechanical ventilatory need and weaning from the mechanical ventilator. In addition, we also investigated the effects on physical and functional independence.

Arguments continue regarding the duration of pulmonary rehabilitation programs. The prolongation of duration of rehabilitation programs was shown to further improve all the parameters that are expected to improve with such programs (16). However, it is known that starting rehabilitation early is more important for ensuring the function, reduction of functional loss, early recovery, ensuring autonomy, and decreasing the hospitalization duration. 
We started rehabilitation on the first day of hospitalization and assessed the evaluations performed at the end of fourth week taking the length of stay in the ICU into consideration. We think further programs added more to the effectiveness.

It was shown that rehabilitation programs in COPD patients have a limited value for the improvement of pulmonary function tests and arterial blood gases but that they have significant effects on the quality of life, dyspnea, functional capacity, anxiety, and depression.

Gezgen et al. (17) evaluated the effect of upper extremity exercise added to the rehabilitation program on pulmonary function and the quality of life in COPD patients, and they indicated that this rehabilitation program shows a positive effect on exercise performance, dyspnea score, and quality of life, whereas no additional effect of upper extremity exercises could be found. Zanotti et al. (18) reported that active limb mobilization and electrical stimulation of muscles in COPD patients bound to mechanical ventilator has positive effects such as the reduction of wheelchair to bed transit time, reduction of respiratory rate, and increase in $\mathrm{O}_{2}$ saturation. We wanted to benefit from the muscle strengthening effect of NMES, which was shown to increase the strength of upper extremity and auxiliary respiratory muscles in prior studies. We observed that electrical stimulation in addition to exercise had a positive effect on cardiorespiratory functions; on the other hand, it did not improve time to leave the ventilator. Electrical stimulation increased the positive effect of exercises when applied to small muscle groups.

Dourado et al. (19) demonstrated the positive effects of rehabilitation on the quality of life in COPD patients. In our study, although we observed a positive impact on the quality of life in both groups, no additional effect of NMES beyond the effect of exercises could be seen.

Implementation of electrical stimulation on peripheral muscles decreases dyspnea and increases exercise tolerance and as well as the quality of life of patients. The muscle contraction obtained with NMES is better tolerated, does not disturb the patient, and has a positive impact on prolonged dependence on mechanical ventilation. Why we could not find this positive effect on functional independence may be related to the clinical situations and demographic properties of patients (20).

There are some limitations in our study. The most important limitations are the small number of patients enrolled and short follow-up. Additional problems in COPD patients who are treated in ICUs may restrict the number of patients enrolled. The short duration of the study was also related with the uncontrolled length of stay in the ICU.

\section{Conclusion}

This study revealed the positive effects of NMES in combination with therapeutic exercises on the cardiorespiratory system in the short run. Longer follow-up studies for further investigations on quality of life are needed in COPD patients who are staying in the ICU.

Ethics Committee Approval: Ethics committee approval was received for this study from the ethics committee of Trakya University Faculty of Medicine.
Informed Consent: Written informed consent was obtained from patients who participated in this study.

Author contributions: Concept - D.K.K., N.T., Design - D.K.K., N.T., M.B., E.T.,; Supervision - D.K.K., N.T., M.B., E.T., N.S.; Resource - D.K.K., N.T., M.B., E.T.; Materials - D.K.K., N.T., E.T.; Data Collection and/or Processing - D.K.K., N.T., N.S.; Analysis and/or Interpretation - D.K.K., N.T., M.B., E.T., N.S.; Literature Search - D.K.K., N.T.; Writing - D.K.K., N.T., M.B.; Critical Reviews - E.T., D.K.K., N.T.

Conflict of Interest: No conflict of interest was declared by the authors.

Financial Disclosure: This study was supported by Trakya University Scientific Research Projects Unit (2009/12).

\section{References}

1. Qaseem A, Wilt TJ, Weinberger SE, Hanania NA, Criner G, van der Molen $\mathrm{T}$, et al. Diagnosis and management of stable chronic obstructive pulmonary disease: a clinical practice guideline update from the American College of Physicians, American College of Chest Physicians, American Thoracic Society, and European Respiratory Society. Ann Intern Med 2011;155:179-91. [CrossRef]

2. Gingter $\mathrm{C}$, Wilm S, Abholz HH. Is COPD a rare disease? Prevalence and identification rates in smokers aged 40 years and over within general practice in Germany. Fam Pract 2009;26:3-9. [CrossRef]

3. Spruit MA, Troosters T, Trappenburg JC, Decramer M, Gosselink R. Exercise training during rehabilitation of patients with COPD: a current perspective. Patient Educ Couns 2004;52:243-8. [CrossRef]

4. Luppi F, Franco F, Beghe B, Fabbri LM .Treatment of chronic obstructive pulmonary disease and its comorbidities. Proc Am Thorac Soc 2008;5:848-56. [CrossRef]

5. Matic I, Danic D, Majeric-Kogler V, Jurjevic M, Mirkovic I, Mrzljak VN. Chronic Obstructive Pulmonary Disease and Weaning of Difficult to wean patients from mechanical ventilation: randomized prospective study. Croat Med J 2007;48:51-8.

6. Clni E, Ambrrosino N. Early physiotherapy in the respiratory intensive care unit. Respir Med 2005;99:1096-104. [CrossRef]

7. Vivodtzev I, Debigaré R, Gagnon P, Mainguy V, Saey D, Dubé A, et al. Functional and muscular effects of neuromuscular electrical stimulation in patients with severe COPD: a randomized clinical trial. Chest 2012;141:716-25. [CrossRef]

8. Vestbo J, Hurd SS, Agustí AG, Jones PW, Vogelmeier C, Anzueto A, et al. Global strategy for the diagnosis, management, and prevention of chronic obstructive pulmonary disease: GOLD executive summary. Am J Respir Crit Care Med 2013;187:347-65. [CrossRef]

9. Jones PW, Quirk FH, Baveystock CM. The St George's Respiratory Questionnaire. Respir Med 1991;85(Suppl B):25-31. [CrossRef]

10. Ware JE Jr, Sherbourne CD. The MOS 36-item short form healthy survey (SF-36). I. Conceptual framework and item selection. Med Care 1992;30:473-83. [CrossRef]

11. Stineman MG, Jette A, Fiedler R, Granger C. Impairment-specific dimensions within the Functional Independence Measure. Arch Phys Med Rehabil 1997;78:636-43. [CrossRef]

12. Pauwels RA, Buist AS, Calverley PM, Jenkins CR, Hurd SS. Global strategy for the diagnosis, management, and prevention of chronic obstructive pulmonary disease. NHLBI/WHO Global Initiative for Chronic Obstructive Lung Disease (GOLD) workshop summary. Am J Respir Crit Care Med 2001;163:1256-76. [CrossRef]

13. Barnes PJ, Kleinert S. COPD-a neglected disease. Lancet 2004;364:564-5. [CrossRef] 
14. Skeletal muscle dysfunction in chronic obstructive pulmonary disease: a statement of the American Thoracic Society and European Respiratory Society. Am J Respir Crit Care Med 1999;159:S1-40.

15. Nava S, Ambrosio N. Rehabilitation in the ICU: the European phoenix. Intensive Care Med 2000;26:841-4. [CrossRef]

16. Green RH, Singh SJ, Williams J, Morgan MD. A randomised controlled trial of four weeks versus seven weeks of pulmonary rehabilitation in chronic obstructive pulmonary disease. Thorax 2001;56:1435. [CrossRef]

17. Gezgen A, Erk M, Müsellim B, Demir T, Mutlu B. The effect of upper extremity exercises on COPD and quality of life. Turk Respir 2001;3:60-5.
18. Zanotti E, Felicetti G, Maini M, Fracchia C. Peripheral muscle strength training in bed-bound patients with COPD receiving mechanical ventilation: effect of electrical stimulation. Chest 2003; 124:292-6.[CrossRef]

19. Dourado VZ, Antunes LC, Tanni SE, de Paiva SA, Padovani CR, Godoy I. Relationship of upper-limb and thoracic muscle strength to 6-min walk distance in COPD patients. Chest 2006;129:551-7. [CrossRef]

20. Nápolis LM, Corsol SD, Neder JA, Malagutil C, Gimenes ACO, Neryl IE. Neuromuscular electrical stimulation improves exercise tolerance in chronic obstructive pulmonary disease patients with better preserved fat-free mass. Clinics 2011;60:401-6. [CrossRef] 